\title{
High daily doses of benzodiazepines among Quebec seniors: prevalence and correlates Mary Y Egan ${ }^{* 1}$, Christina Wolfson ${ }^{2}$, Yola Moride3 and Johanne Monette4
}

Address: ${ }^{1}$ Faculty of Health Sciences 451 Smyth Road University of Ottawa Ottawa, Canada, ${ }^{2}$ Department of Epidemiology and Biostatistics McGill University Montreal, Canada, 3Faculty of Pharmacy University of Montreal Montreal, Canada and 4Department of Geriatrics Jewish General Hospital Montreal, Canada

E-mail: Mary Y Egan* - megan@uottawa.ca; Christina Wolfson - tinaw@epid.jgh.mcgill.ca; Yola Moride - yola.moride@UMontreal.CA; Johanne Monette - mem2@musica.megill.ca

*Corresponding author

Published: 23 November 2001

BMC Geriatrics 200I, I:4
Received: 5 July 2001

Accepted: 23 November 2001

This article is available from: http://www.biomedcentral.com//47I-23/8/I/4

(C) 200 I Egan et al; licensee BioMed Central Ltd. Verbatim copying and redistribution of this article are permitted in any medium for any non-commercial purpose, provided this notice is preserved along with the article's original URL. For commercial use, contact info@biomedcentral.com

\begin{abstract}
Background: Use of high daily doses of benzodiazepines is generally contraindicated for seniors. While both patient and physician factors may influence the use of high daily doses, previous research on the effect of patient factors has been extremely limited. The objectives of this study were to determine the one year prevalence of use of high daily doses of benzodiazepines, and examine physician and patient correlates of such use among Quebec community-dwelling seniors.

Methods: Patient information for 1423 community-dwelling Quebec seniors who participated in the Canadian Study of Health and Aging was linked to provincial health insurance administrative data bases containing detailed information on prescriptions received and prescribers.

Results: The standardized one year period prevalence of use of high daily doses of benzodiazepines was $7.9 \%$. Use of high daily doses was more frequent among younger seniors and those who had reported anxiety during the previous year. Patients without cognitive impairment were more likely to receive high dose prescriptions from general practitioners, while those with cognitive impairment were more likely to receive high dose prescriptions from specialists.
\end{abstract}

Conclusion: High dose prescribing appears to be related to both patient and physician factors.

\section{Background}

While there continues to be concern regarding the use of benzodiazepines with seniors [1], most experts agree that these drugs can be relatively effective and safe when prescribed and taken in an appropriate manner [2]. Dose is an important characteristic in determining the appropriateness of a benzodiazepine prescription. We examined the prevalence and correlates of the use of high daily does of benzodiazepines among a group of seniors in Quebec.
The use of high daily doses of benzodiazepines by seniors is associated with a number of adverse outcomes including hip fracture [3], and motor vehicle accidents [4,5], as well as accidental falls, accidental poisonings, hospitalizations for depression and other psychiatric events and attempted and completed suicides [6]. There is evidence that dosage may be a more important risk for femoral fracture than benzodiazepine half-life [3,7], and may be especially problematic with oxidative benzodiazepines [8]. Due to the widespread use of benzodiazepines 
among seniors, even a relatively low prevalence of high dose use may have a substantial impact on public health. Research to investigate the prevalence and correlates of the use of high daily doses is therefore extremely important.

To date, three studies of the prevalence and correlates of high dose benzodiazepine prescribing to Canadian seniors have been reported. In British Columbia, examination of the provincial drug plan data bases revealed that four percent of British Columbia seniors received prescriptions for daily doses of $20 \mathrm{mg}$ diazepam equivalent or more during 1990 [9]. The average daily dose of benzodiazepines received by Nova Scotia seniors between 1993 and 1996, according to the provincial administrative drug data base, was found to be generally higher than recommended geriatric doses. However, extreme variation in the daily doses measured led the authors to question the validity of the results [10]. When benzodiazepine hypnotic prescriptions were examined by selected pharmacists in Ontario and Quebec, approximately one-third of triazolam and oxazepam prescriptions and two-thirds of flurazepam prescriptions were considered high dose [11]. Lack of a recognized standard in these studies defining a high daily dose, as well as limitations in the information contained in provincial data bases, have made it difficult to compare the prevalence of high dose prescribing over time and across provinces.

A limited number of patient and prescriber characteristics have been examined as potential correlates of use of high daily doses, including patient age and physician gender, specialty status and prescribing tendencies. Younger seniors were more likely to use high daily doses $[11,12]$. Male physicians were somewhat more likely to prescribe high doses than female physicians. General practitioners were more likely to write high dose prescriptions as were physicians who were frequent prescribers of benzodiazepines [9].

Interpretation of the findings regarding physician factors associated with high daily dose prescribing are difficult since, in these studies, there was no consideration of patient characteristics which might inform dosing. For example, the use of a higher than recommended daily dose may be required for an individual with severe anxiety, one who has developed tolerance for the drug with long-term use [13], or a heavier individual [14]. Lower doses are recommended for individuals with cognitive impairment $[15,16]$ or those in poor health [17]. Such characteristics may confound or alter relationships between physician characteristics and prescribing behaviour. A clearer picture of physician characteristics associated with high dose prescribing, and any patient characteristics which affect prescribing decisions, is im- perative for the development of programs to lessen high dose prescribing.

The objectives of this study were to determine the prevalence of use of high daily doses among Quebec seniors using a standard definition of high daily doses and to evaluate the association between high daily dose prescribing and physician characteristics while also considering patient factors. This study was carried out using patient data from the first wave of the Canadian Study of Health and Aging (CSHA1) [18]. The CSHA1 was a major nation-wide study carried out primarily to determine the prevalence of dementia in Canada. For the present study, data from the CSHA1 were linked to prescribing data from the Quebec provincial health insurance drug data base.

\section{Methods \\ Subjects}

Quebec community-dwelling seniors who participated in the screening phase of the first wave of the Canadian Study of Health and Aging (CSHA1) [18] formed the study population. Eligible individuals were those 65 years of age and older on October 1, 1990, who lived in Chicoutimi, Montreal, Quebec City and Sherbrooke, or the rural areas surrounding these cities. Exclusion criteria included lack of fluency in English or French, presence of a life-threatening illness and residence in a nursing home, long-stay hospital or other collective dwelling (e.g. a convent). Subjects were selected from provincial health insurance plan records using a stratified random sample. Of those 2549 eligible Quebec subjects who could be contacted, 1778 (69.8\%) were screened for dementia between February 1, 1991 and May 1, 1992 using the Modified Mini-Mental Status examination (3MS) [19].

\section{Data linkage}

During the CSHA1 screening interviews Quebec subjects were asked to provide their health insurance (RAMQ) numbers. Information from CSHA1 and RAMQ was linked using subjects' health insurance numbers. RAMQ guidelines specified that information could not be released for subjects who possessed a unique profile of characteristics which could allow identification of those subjects following data linkage. It was therefore necessary to group CHSA1 subjects into characteristic-defined subgroups containing multiple members. A file containing these data was then forwarded to the RAMQ Statistical Services Department who carried out the linkage and replaced each subject's individual RAMQ number with a scrambled identifying code. 
Table I: Defined Daily Doses

\begin{tabular}{|c|c|c|c|c|c|}
\hline Benzodiazepine & DDD (mg) & $\begin{array}{l}\text { Diazepam equivalent } \\
(\mathrm{mg})(2 \mathrm{I})\end{array}$ & $\begin{array}{l}\text { CPS (22) maximum } \\
\text { adult daily dose }(\mathrm{mg})\end{array}$ & $\begin{array}{c}\text { Maximum geriatric dose - } \\
\text { (Jenike) [26] }\end{array}$ & $\begin{array}{l}\text { Maximum geriatric dose } \\
\text { (Beers et al.) [27] }\end{array}$ \\
\hline alprazolam & 1 & 10 & 3 & 0.5 & NG \\
\hline bromazepam & 10 & 16.67 & 30 & NG & NG \\
\hline $\begin{array}{r}\text { chlordiazepox- } \\
\text { ide }\end{array}$ & 30 & 15 & 40 & 30 & NR \\
\hline diazepam & 10 & 10 & 40 & 10 & NR \\
\hline flurazepam & 30 & 5 & 30 & NG & NR \\
\hline lorazepam & 2.5 & 12.5 & 4 & 4 & NG \\
\hline nitrazepam & 5 & 2.5 & 10 & NG & NG \\
\hline oxazepam & 50 & 16.67 & 120 & 30 & 30.00 \\
\hline temazepam & 20 & 3.33 & 30 & 30 & NG \\
\hline triazolam & 0.25 & 5 & 0.5 & 0.5 & 0.25 \\
\hline
\end{tabular}

Note. DDD = Defined Daily Dose; CPS = Compendium of Pharmaceutical Specialties; NG=not given; NR=not recommended

\section{Measurements}

Subjects were categorized according to whether they had filled one of more prescriptions for benzodiazepines during the 365 days following screening and then further categorized as to whether or not any of their benzodiazepine prescriptions were for high daily doses. A prescription was defined as a high daily dose if the prescribed dosage was higher than the Defined Daily Dose (DDD) for that particular benzodiazepine [20]. The DDD is the unit of daily drug consumption set by the World Health Organization (WHO) to allow estimation regional per capita consumption of drugs regions when only sales data are available. In this study the DDDs for benzodiazepines were used to differentiate a standard dose of the drug and a high dose. The DDD's for study benzodiazepines are compared with the manufacturers' prescribing guidelines in use just prior to the study period [21] and the diazepam equivalents [22] in Table 1.

Patient gender, age (66-69, 70-74, 75-79, 80+ years), subjective anxiety (whether the patient reported "problems with his/her nerves" during the year prior to screening), and score on the $3 \mathrm{MS}(<78$ versus $78+$, maximum score in cognitively intact $=100$ ) were extracted from CSHA1 data. Using all prescriptions filled during the year prior to CSHA1 screening, a Chronic Disease Score (CDS) [23] was calculated for each patient. The CDS provides a measure of health status by considering the number and severity of chronic diseases for which a patient is receiving pharmacotherapy. A score of 4 or more represents relatively poor health. Higher scores on the CDS have been associated with increased risk of hospitalization and death $[23,24]$. In addition, use of benzodiazepines during the previous year was ascertained by examining the RAMQ data for the presence of a benzodi- azepine prescription during the 365 days prior to CSHA1 screening.

The most frequent prescriber of high or low dose benzodiazepine prescriptions was identified for each subject. The prescriber's year of graduation $(1980+, 1970-79$, 1960-69, 1959 or earlier), gender and whether the physician was a generalist (i.e. general practitioner or family physician) or a specialist were derived from RAMQ records.

\section{Data analysis}

The one year period prevalence of use of high daily doses was determined and standardized by age and gender to the 1991 Quebec population.

Among subjects who used benzodiazepines during the year following screening, the odds ratio of use of high daily doses associated with each patient and prescriber characteristic was calculated. Backward logistic regression was used to produce a model of main effects. Then patient factors which potentially modified the relationships between physician characteristics and use of high daily doses were identified, added to and tested in the model of main effects. Significant main effects and interaction terms were retained in the final model. All calculations were performed using SAS version 6.04 software [25].

\section{Ethics}

Ethics approval for the present study was granted by the Research Ethics Committee of the Sir Mortimer B. DavisJewish General Hospital, November 3, 1995. 


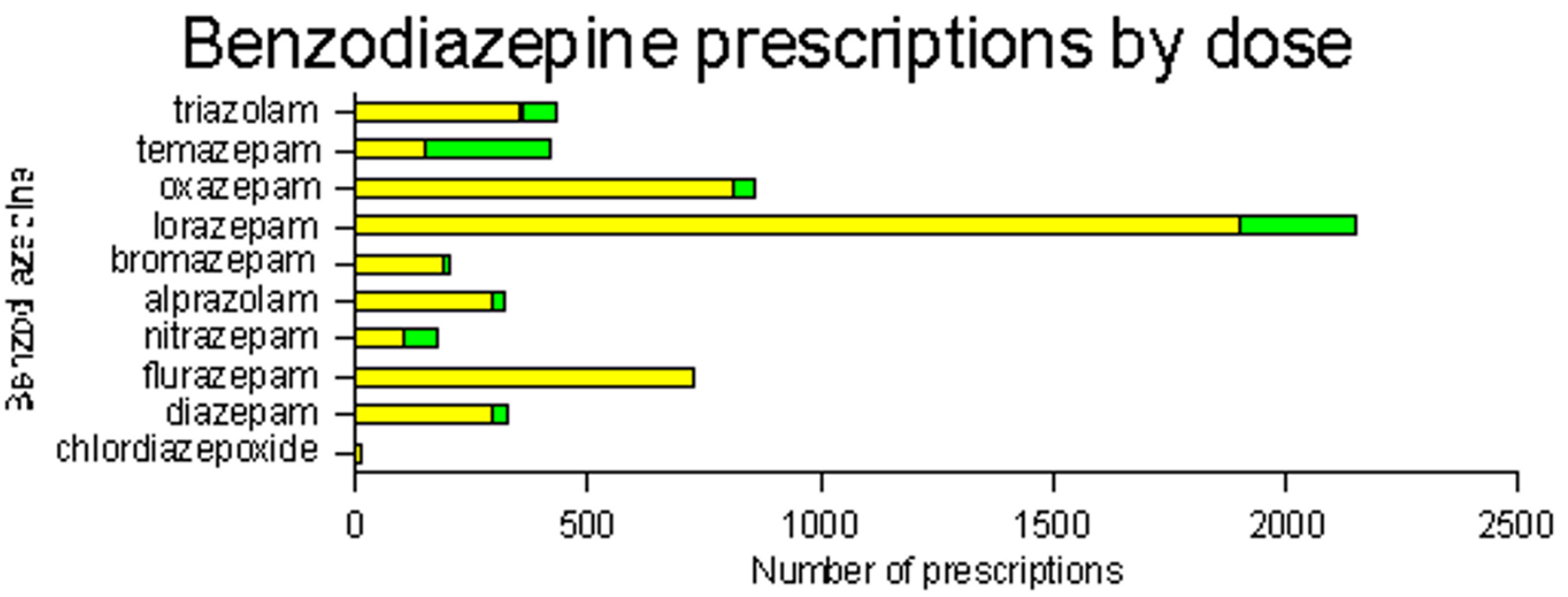

Defined Daily Dose or less

\section{High dose}

Figure I

Benzodiazepine prescriptions by dose

\section{Results}

Of the 1778 Quebec CSHA1 community-dwelling subjects who received a screening interview, 1460 provided a RAMQ number. Valid RAMQ numbers and sufficient data on patient characteristics were available for 1423 subjects who thus formed the study sample. When these 1423 subjects were compared with the 355 subjects not included in the data linkage, subjects included in the linkage were more likely to be female, and more likely to have screened negative for cognitive impairment. However, linked and non-linked subjects did not differ by age at screening or anxiety (data not shown).

Of the 1423 subjects whose CSHA1 data were linked to RAMQ records, 607 (42.7\%) filled at least one prescription for a benzodiazepine during the 12 months following CSHA1 screening (standardized one year prevalence: $41.3 \%)$.

Of the 5638 benzodiazepine prescriptions, 787 (14.0\%) were for high daily doses. The proportion of high dose prescriptions varied by type of benzodiazepine (Figure 1). Of the 1423 study subjects, 108 (7.6\%) filled at least one high daily dose prescription (standardized one year prevalence: $7.9 \%$ ).

The above analysis considered single drugs only. One hundred and twenty-three subjects received more than one type of benzodiazepine on a given day. In a post hoc analysis, all distinct benzodiazepines received by a given subject on a particular day were identified and the proportion of the DDD of each was summed. Using this approach, 132 (9.3\%) subjects were identified as high dose users (standardized one year prevalence: 9.6\%).

When unadjusted associations between use of high daily doses and patient and physician factors were considered for the 607 benzodiazepine users (Table 2), use of high daily doses was more common among patients who had reported anxiety and those who had previously used benzodiazepines.

The final model predicting use of high daily doses included patient age, anxiety and cognitive status and physician specialty status with an interaction between the latter two factors (Table 3). Specifically the model indicates that patients reporting anxiety and patients 66-74 years of age are more likely to receive high daily doses. Specialists are less likely than general practitioners to prescribe high doses when the patient does not have cognitive impairment, but more likely to prescribe them when the patient does have cognitive impairment.

\section{Discussion}

The one year prevalence of use of high daily doses found in this study was $7.9 \%$. A lower prevalence of use of high doses (i.e. $4 \%$ ) was found in the only comparable study of British Columbia seniors [4]. However, in the British Columbia study, the one year prevalence of any use of benzodiazepines was $23.4 \%$, compared with $41.3 \%$ in the 
Table 2: Unadjusted odds ratios for patient and prescriber characteristics and use of high daily doses

\begin{tabular}{|c|c|c|c|c|c|c|c|c|}
\hline & & & \multicolumn{2}{|c|}{ High daily dose } & \multicolumn{2}{|c|}{ Less than high daily dose } & \multirow[b]{2}{*}{ Odds ratio } & \multirow[b]{2}{*}{$95 \% \mathrm{Cl}$} \\
\hline & & & $\mathrm{n}$ & (\%) & $\mathrm{n}$ & (\%) & & \\
\hline \multirow[t]{8}{*}{ Prescriber } & Gender & female & II & $(10.2)$ & 68 & $(13.6)$ & 1 & Reference \\
\hline & & male & 97 & (89.8) & 431 & (86.4) & 1.39 & $0.7 I-2.73$ \\
\hline & Year of graduation & $1980+$ & 15 & (13.9) & 80 & $(16.0)$ & I & Reference \\
\hline & & $1970-79$ & 40 & $(37.0)$ & 211 & $(42.3)$ & 1.01 & $0.53-1.93$ \\
\hline & & $1960-69$ & 28 & $(25.9)$ & 107 & $(21.4)$ & 1.4 & $0.70-2.79$ \\
\hline & & pre 1960 & 25 & $(23.1)$ & 101 & $(20.2)$ & 1.32 & $0.65-2.67$ \\
\hline & Specialist & no & 93 & $(18.6)$ & 408 & $(81.4)$ & 1 & Reference \\
\hline & & yes & 15 & $(14.2)$ & 91 & $(85.8)$ & 0.72 & $0.40-1.31$ \\
\hline \multirow[t]{14}{*}{ Patient } & Gender & female & 70 & $(64.8)$ & 357 & (7I.5) & 1 & Reference \\
\hline & & male & 38 & $(31.5)$ & 142 & $(28.5)$ & 1.37 & $0.88-2.12$ \\
\hline & Age & $66-69$ & 22 & $(20.4)$ & 83 & $(16.6)$ & 1 & Reference \\
\hline & & $70-74$ & 34 & $(23.6)$ & 110 & $(22.0)$ & 1.17 & $0.64-2.14$ \\
\hline & & $75-79$ & 27 & $(31.5)$ & 143 & $(28.7)$ & 0.71 & $0.38-1.33$ \\
\hline & & $80+$ & 25 & $(23.1)$ & 163 & (32.7) & 0.58 & $0.31-1.09$ \\
\hline & Anxiety & no & 62 & (57.4) & 353 & (70.7) & 1 & Reference \\
\hline & & yes & 46 & $(42.8)$ & 146 & $(29.3)$ & 1.79 & I. $17-2.75$ \\
\hline & $3 M S$ & $>78$ & 82 & (75.9) & 361 & $(72.3)$ & 1 & Reference \\
\hline & & $<78$ & 26 & $(24.1)$ & 138 & $(27.7)$ & 0.83 & $0.5 \mathrm{I}-1.34$ \\
\hline & CDS & $<4$ & 92 & (85.2) & 417 & $(83.6)$ & 1 & Reference \\
\hline & & $>4$ & 16 & $(14.8)$ & 82 & $(16.4)$ & 0.88 & $0.50-1.58$ \\
\hline & previous use & no & 6 & $(5.6)$ & 65 & $(13.0)$ & 1 & Reference \\
\hline & & yes & 102 & $(94.4)$ & 434 & $(87.0)$ & 2.55 & $1.07-6.04$ \\
\hline
\end{tabular}

Table 3: Final model predicting use of high daily doses of benzodiazepines

\begin{tabular}{rrrr}
\hline \multicolumn{1}{c}{ Variable } & Parameter estimate & Standard error & P-value \\
& & & \\
\hline Intercept & -1.2676 & 0.1889 & \\
Anxiety (yes) & 0.5874 & 0.2219 & 0.008 \\
Age (75+ years) & -0.5651 & 0.2195 & 0.01 \\
3MS (<78) & -0.3952 & 0.2757 & 0.1518 \\
Specialist (yes) & -0.7598 & 0.3643 & 0.037 \\
3MS* Specialist & 1.7736 & 0.7013 & 0.0114 \\
& & & \\
\hline
\end{tabular}

present study. Thus, the proportion of high dose use among benzodiazepine users in British Columbia was $17 \%$ compared to $19 \%$ among the Quebec seniors in this study. While the overall prevalence of use of high doses was greater among Quebec seniors, the proportion of high dose use among benzodiazepine users was similar in the two provinces.

Results of this study seem to indicate that physicians tended to avoid high daily dose prescriptions for patients over 74 years of age, and were more likely to prescribe high daily doses if the patient had chronic anxiety. Contrary to previous reports $[4,7]$, we did not find a statistically significant relationship between high daily dose prescribing and male physician gender or older age, as reflected in year of graduation. However, relationships were in the same direction as those reported previously.

While earlier studies demonstrated that specialists are less likely to prescribe high daily doses than generalists [4], we found that this may be true only with cognitively intact patients. This study provides evidence that generalists may be more likely than specialists to prescribe high daily doses to seniors without cognitive problems, but less likely than specialists to prescribe high daily doses to those with cognitive impairment.

The limitations of this study included potential problems due to cross-sectional methodology, use of the patient as the unit of analysis, and use data on drug dispensing as a proxy measure of drug use. Since both use of high daily doses and patient and physician characteristics were measured at the same time, it is impossible to make any kind of statement of causality. For example, patients with cognitive impairment who required high daily doses 
may have been more likely to present to specialists than to general practitioners. Since analysis was carried out at the patient level, selected prescribers may not be representative of high dose prescribers in general. As well, where physicians prescribed to two or more patients, significance of associations may been overestimated. It must also be noted that administrative data bases, such as the one used, contain information on prescriptions as filled. Patients may consume more or less of these medications over a shorter or more prolonged period of time. While the RAMQ data base does contain a variable for dosage which was used in the determination of dose in this study, patients could have taken the drugs in a way other than was prescribed.

Another potential limitation of the study is the use of the DDD as an indicator of high dose prescribing. The DDD was constructed to allow for an estimation of per capita consumption of specific drugs based on aggregate records such as sales data [15]. It was therefore originally conceived of as a technical measure, not a clinical one. However, the fact that it is both an internationally recognized measure and one that allows for dosage comparisons between drug categories, makes it an excellent choice if one wishes to compare prevalence of use at various dosage level over time and across regions. Clinically, use of more than three-quarters of the DDD has been found to be associated with increase risk of hip fracture among benzodiazepine users 55 years of age and older [1].

Finally, it must also be noted that this data reflects benzodiazepine use among Quebec seniors during a one period sometime between 1991 and 1993, the actual time period dependent upon time of enrollment into the CSHA1. Given increasing reports of the risks associated with benzodiazepine use in the elderly, as well as campaigns designed to optimize prescribing, one could expect that high dose prescribing is on the wane. However, analysis of benzodiazepine prescriptions to seniors during 1997 indicate that the proportion of high dose prescriptions remains virtually unchanged (Monette, Grad, Tamblyn, Jacques, LeCruguel \& Avorn, manuscript in preparation.).

While the use of high daily doses of benzodiazepines is generally contraindicated for seniors, this study provides evidence that such use is relatively common among the elderly in Quebec. Those at highest risk for such use were younger seniors and those who had reported anxiety during the previous year. As well, this study indicates that the relationship between physician specialty status and high dose prescribing is more complex than previously believed, and may be associated with patient cognitive impairment, with those patients suffering from cognitive impairment less likely to receive high daily doses from generalists.

There are implications of these results for basic and continuing medical education. First, since we found no association between year of graduation and high dose prescribing, it is reasonable to assume that it is worthwhile to further emphasize the importance of keeping dosage low for older patients. As well, our finding that specialists may be more likely to write high dose prescriptions in some situations warrants further investigation. There may be confounding factors for the finding that these physicians prescribed higher doses for cognitively impaired patients (e.g. more severe sleep problems), or it may be important to target this area of their practice for continuing education.

\section{Competing interests}

None declared.

\section{Acknowledgements}

The data reported in this article were collected as part of the Canadian Study of Health and Aging. This was funded by the Seniors' Independence Research Program, administered by the National Health Research and Program of Health and Welfare Canada (Project No. 6606-3954-MC (S)). The study was coordinated through the University of Ottawa and the federal government's Laboratory Centre for Disease Control. Linkage of CSHAI data and RAMQ files for the present study was financed by the Fonds de la recherche en santé du Québec (FRSQ) Équipe Prioritaire "Epidemiologic approaches to the study of dementia in the elderly". The present study was made possible in part by Health Canada through a National Health $\mathrm{Re}$ search and Development Program (NHRDP) Research Training Award.

The authors wish to acknowledge Dr Roland Grad who developed the algorithm used to determine the Chronic Disease Score from RAMQ data.

\section{References}

I. North DA, McAvoy BR, Powell AM: Benzodiazepine use in general practice - is it a problem? New Zealand Med J 1992, 1 05:287-9

2. Rosser WW: Anxiety over benzodiazepines. Can Fam Phys I995, 41:760-5

3. Herings RMC, Stricker BHC, de Boer A, Bakker A, Sturmans F: Benzodiazepines and the risk of falling leading to femur fractures. Arch Intern Med 1995, I55:1801-7

4. Barbone F, McMahon AD, Davey PG, Morris AD, Reid IC, McDevitt DG, MacDonald TM: Association of road-traffic accidents with benzodiazepine use. Lancet 1998, 352(9137): |33|-6

5. Ray WA, Fought RL, Decker MD: Psychoactive drugs and the risk of injurious motor vehicle crashes in elderly drivers. Am J Epidemiol 1992, 136:873-88

6. Neutel Cl, Downey W, Senft D: Medical events after a prescription for a benzodiazepine. Pharmacoepidemiol Drug Saf I995, 4:6373

7. Wang PS, Bohn RL, Glynn RJ, Mogun H, Avorn J: Hazardous benzodiazepine regimens in the elderly: effects of half-life, dosage, and duration on risk of hip fracture. Am J Psych; I 58:892-8

8. Sgadari A, Laplane KL, Mor V, Landi F, Bernabei R, Gambassi G: Oxidative and non-oxidative benzodiazepines and the risk of femur fracture. The Systematic Assessment of Geriatric Drug Use Via Epidemiology Study Group.J Clin Psychopharmacol 2000, 20:234-9

9. Thomson M, Smith WA: Prescribing benzodiazepines for noninstitutionalized elderly. Can Fam Phys 1995, 41:792-8

10. Rojas-Fernandez CH, Carver D, Tonks R: Population trends in the prevalence of benzodiazepine use in the older population of Nova Scotia: A cause for concern? Can J Clin Pharmacol 1999. 6: $149-156$ 
II. Baker MI, Oleen MA: The use of benzodiazepine hypnotics in the elderly. Pharmacotherapy 1988, 8:24I-7

12. Shorr RI, Bauwens SF: Effects of patient age and physician training on choice and dose of benzodiazepine hypnotic drug. Arch Intern Med 1990, 150:293-5

13. Gorman JM, Papp LA: Chronic anxiety: deciding length of treatment. J Clin Psychiatry I 990, 5 I (SuppI): I I-I 5

14. Holford NHC, Benot LZ: Pharmacokinetics and pharmacodynamics: Dose selection and the time and course of drug administration. In: Katzung BG, editor. Basic and clinical pharmacology (7th edition). Stanford: Appleton \& Lange, 199834-49

15. Devanand DP: Behavioral complications and their treatment in Alzheimer's disease. Geriatrics 1997, 52 Suppl 2:S37-39

16. Meyer BR: Benzodiazepines in the elderly. Med Clin North Am 16, 66:1017-35

17. Edwards JG: Adverse effects of antianxiety drugs. Drugs 198।, 22:495-514

18. Canadian Study of Health and Aging Working Group: Canadian Study of Health and Aging: study methods and prevalence of dementia. Can Med Assoc ] 1990, I 50:899-9I2

19. Teng EL, Chui HC: The modified mini-mental state (3MS). J Clin Psychiatry 1987, 48:314-8

20. World Health Organization: WHO Collaborating Centre for Drug Statistics Methodology ATC Index with DDD's. Oslo:WHO; 1997

21. Canadian Pharmaceutical Association: Compendium of Pharmaceuticals and Specialities. Volume 29. Ottawa:Canadian Pharmaceutical Association; 1990

22. Teboul E, Chouinard G: A guide to benzodiazepine selection. Part I: Pharmacological aspects. Can J Psychiatry 1990, 35:700710

23. Von Korff M, Wagner EH, Saunders K: A chronic disease score from automated pharmacy data. J Clin Epidemiol 1992, 45:197203

24. Johnson RE, Hornbrook MC, Nichols GA: Replicating the Chronic Disease Score (CDS) from automated pharmacy data. J Clin Epidemiol 1994, 47:1191-1199

25. SAS for Personal Computers [computer program] Release 6.03. Cary (NC): SAS Institute Inc; 1987

26. Jenike MA: Handbook of geriatric psychopharmacology. Littleton, MA: PSG, 1985

27. Beers MH, Ouslander JG, Rollingher I, Reuben DB, Brooks J, Beck JC: Explicit criteria for determining inappropriate medication use in nursing home residents. Arch Intern Med 1991, I 5 I:182532

\section{Publish with BioMed Central and every} scientist can read your work free of charge

"BioMedcentral will be the most significant development for disseminating the results of biomedical research in our lifetime." Paul Nurse, Director-General, Imperial Cancer Research Fund

Publish with BMC and your research papers will be:

- available free of charge to the entire biomedical community

- peer reviewed and published immediately upon acceptance

- cited in PubMed and archived on PubMed Central

- yours - you keep the copyright 